\title{
Commentary: Spatial Olfactory Learning Contributes to Place Field Formation in the Hippocampus
}

\author{
Mikhail A. Lebedev ${ }^{1,2 *}$ and Alexei Ossadtchi ${ }^{2}$ \\ ${ }^{1}$ Department of Neurobiology, Duke University, Durham, NC, United States, ${ }^{2}$ Center for Bioelectric Interfaces of the Institute \\ for Cognitive Neuroscience of the National Research University Higher School of Economics, Moscow, Russia
}

Keywords: olfactory response, hippocampus, place cells, place cell remapping, scent marking, navigation

\section{A commentary on}

Spatial Olfactory Learning Contributes to Place Field Formation in the Hippocampus

by Zhang, S., and Manahan-Vaughan, D. (2015). Cereb. Cortex 25, 423-432. doi: $10.1093 /$ cercor/bht239

The discovery of place-representing neurons in the hippocampal formation has been recognized by the Nobel Committee as a paradigm shift in Neuroscience (Burgess, 2014). Here we call attention to an innovative paper of particular note (Zhang and Manahan-Vaughan, 2015) that added important findings to this field of study.

Zhang and Manahan-Vaughan investigated the contribution of olfactory cues to the formation of place fields in hippocampal neurons. For this purpose, they put male Wistar rats in the darkness into a $80 \times 80 \mathrm{~cm}$ square box. Four odors (orange, vanilla, almond, and lemon) were placed into the quadrants of the arena. Chocolate crumbs were scattered across the arena to encourage exploratory behavior. The researchers observed the formation of stable place fields in the hippocampal neurons, even though visual cues were unavailable to the rats. The place fields rotated when the odor placements were rotated, and remapped when the odors were shuffled. The authors concluded that "despite the less precise nature of olfactory stimuli compared with visual stimuli, these can substitute for visual inputs to enable the acquisition of metric information about space."

This is a significant finding because it provides insights on the role of olfaction in the formation of hippocampal representation of space, or “cognitive maps” using the terminology of O'Keefe and Nadel (1978). O'Keefe's experiments utilized a neuro-ethological approach, where neuronal responses were examined during natural animal behaviors, such as spatial exploration and foraging by unrestrained rodents (O'Keefe and Nadel, 1978). O'Keefe's key discovery was the finding of place cells in the rat hippocampus that discharged when a rat entered a particular spatial location (O'Keefe and Dostrovsky, 1971). O'Keefe and his colleagues reported that place cells responded to environmental visual cues (O'keefe and Conway, 1978). Moser et al. (2008) commented on this development, "Early on, it became apparent that place fields are strongly influenced by distal sensory cues." Following this discovery, many studies focused on the role of vision in place field formation, and the integration of visual inputs with vestibular and proprioceptive inputs during path integration (Markus et al., 1994; Wiener et al., 1995; Arleo and Gerstner, 2000; Moser et al., 2008). The relationship of olfaction and place fields was less studied. Several recent studies employed virtual reality tasks to eliminate the contribution of olfaction entirely and to show that vision alone can generate place fields (Harvey et al., 2009; Dombeck et al., 2010; Chen et al., 2013; Domnisoru et al., 2013; Ravassard et al., 2013; Aronov and Tank, 2014; Aghajan et al., 2015). Given the predominance of studies based on visual environments, the Zhang and Manahan-Vaughan study of olfaction is a contribution to a less explored field.

While most of the Zhang and Manahan-Vaughan findings are convincing, the paper does not contain a thorough analysis of rat navigation traces. This is unfortunate because rodents generate 
highly structured navigation patterns (Golani et al., 1993; Drai and Golani, 2001; Benjamini et al., 2010; Yaski et al., 2011) characterized by the establishment of a home base, tendency to stay near the walls and corners, and locomotion periods intermingled with stops and turns. It seems reasonable to hypothesize that in the experiments of Zhang and ManahanVaughan, rats behaved differently in the odor locations compared to the other parts of the arena. For example, they could have exhibited specific sniffing patterns; additionally, they could have explored some odors longer than the others. Furthermore, since navigation goal was to obtain chocolate crumbs, rats could have developed a specific foraging strategy, such as of avoiding locations that have been already visited and seeking food at new locations. Analysis of navigation statistics is important because navigation patterns could have influenced the measurements of the neuronal place fields. For example, if the rats frequently visited some places in the arena but rarely visited the others, measurements of neuronal rates are more reliable for the former locations than for the latter. It is not entirely clear why Zhang and Manahan-Vaughan displayed neuronal place fields using a circular area although the arena had a square shape. Finally, the duration of each analyzed session was $5 \mathrm{~min}$, the time that may have been insufficient for a rat to cover all places in the arena. These issues are present not only in the study of Zhang and Manahan-Vaughan; most of the studies on place cells and grid cells contain little detail on navigation traces and different behaviors exhibited by rodents during navigation, even though non-random navigation patterns are often visible in the published figures that display animal traces.

Notably, the study of Zhang and Manahan-Vaughan contains no data on the behavioral responses to different odors. Were the sniffing patterns (Welker, 1964; Clarke et al., 1970; Youngentob et al., 1987; Fonio et al., 2015) altered? Were the spatiallydependent neuronal responses phase locked to the sniffing? Obtaining answers to these questions is important because different sniffing (and postural, and locomotion) patterns in specific parts of the arena could have produced distinct neuronal responses, leading to an erroneous conclusion of the presence of a purely spatial map in the hippocampus, irrespective of the behaviors exhibited by the animals. In reality, the neuronal patterns may have represented neuronal responses to specific behaviors, not a spatial map per se.

Lastly, Zhang and Manahan-Vaughan do not mention scent marking behavior, which is prevalent in rodents, particularly in the male animals (Johnson, 1973; Tomlinson and Johnston, 1991; Wallace et al., 2002; Stopka and MacDonald, 2003; Hurst and Beynon, 2004; Kulvicius et al., 2008). Based on the findings of Zhang and Manahan-Vaughan, it is reasonable to suggest that odors resulting from scent marking could have contributed to the formation of hippocampal spatial maps. Such a suggestion would be consistent with O'Keefe's neuro-ethological approach because male rodents (predominantly used in studies on place fields) utilize scent marks to advertise their ownership of a territory and attract females (Roberts et al., 2010, 2012; Thonhauser et al., 2013). Additionally, rodents respond to odor cues during navigation (Lavenex and Schenk, 1998; Wallace et al., 2002; Porter et al., 2005; Khan et al., 2012), although vision dominates over olfaction in certain tasks (Small, 1901; Olton and Collison,
1979; Lavenex and Schenk, 1996; Maaswinkel and Whishaw, 1999).

Overall, Zhang and Manahan-Vaughan agreed with the conventional notion that "visuospatial contexts comprise a key element in the formation of place fields" and attributed only a secondary role to olfaction. Yet, they cited several studies showing that the contribution of olfaction could be quite significant. For example, blind rats exhibit place fields (Save et al., 1998). Additionally, stability of place fields improves when the recording box is not cleaned in between the experiments (Save et al., 2000). Zhang and Manahan-Vaughan themselves reported that hippocampal neurons exhibited place fields even when no odors were experimentally placed in the recording box. Moreover, these place fields persisted after the rats were taken out of the box and then put back while the light was off. Since this manipulation should have disoriented the rats, the fact that the place fields remained indicates that some sensory cues were left in the box, possibly scent marks spared by the cleaning procedure. Most of the labs involved in this research clean the behavioral arena in between the experimental sessions. However, their cleaning procedures may be insufficient for eliminating the scent marks entirely. For example, the following cleaning procedure is reported in the pioneering study of the entorhinal grid cells (Fyhn et al., 2004): "Each trial lasted $10 \mathrm{~min}$. Before and after each trial, the rat rested on a pedestal for 5-10 min, and the floor was cleaned with a damp cloth." This may qualify only as a partial cleaning that does not remove odors completely (Gray and Hurst, 1995). Additionally, even if the cleaning worked well, scent marks may have gradually accumulated in the arena during the 10-min experimental session.

Historically, Ramon Cajal initially proposed that the hippocampus was a structure with an essential role in olfaction (DeFelipe and Jones, 1988; Vanderwolf, 2001). Cajal's theory was, however, abandoned after Brodal questioned the existence of olfactory inputs to the hippocampus and pointed to the studies showing that hippocampal lesions did not affect behaviors conditioned by odors (Brodal, 1947). Olfactory projections to the hippocampal formation were later shown (Krettek and Price, 1977; Luskin and Price, 1983; Room et al., 1984; Schwerdtfeger et al., 1990); as well as electrophysiological responses to odors (Wilson and Steward, 1978; Vanderwolf, 1992; Biella and De Curtis, 2000; Insausti et al., 2002). Yet, only Vanderwolf continued to believe that the hippocampal formation processed odors instead of constructing a spatial map (Vanderwolf, 1992, 2001), whereas the mainstream theory described the hippocampal formation a hierarchically high region that constructs a cognitive map of space based on multiple sensory inputs (Moser and Moser, 2013). Curiously, this theory does not explain why cetaceans orient in space well (Thomas and Kastelein, 2013) despite having a small hippocampus (Patzke et al., 2015). Conspicuously, their small size of the hippocampus correlates with the absence of olfaction in these animals (Breathnach, 1960). Additionally, Jacobs (2012) proposed that rodents rely on olfaction when they navigate in space, and that olfactory regions act as a scaffold for the visual representation of space. In agreement with this view, olfactory bulbectomy severely impairs navigation in rats (van Rijzingen et al., 1995). 
Based on the study of Zhang and Manahan-Vaughan and the other studies on the processing of olfactory information in the hippocampus (Shapiro et al., 1997; Save et al., 2000; Deshmukh and Bhalla, 2003; MacDonald et al., 2013), one could question the purely visual origin of the hippocampal place cells reported in some of the previous publications, particularly the ones with inadequate controls for scent marks and different navigationrelated behaviors, such as sniffing (Welker, 1964; Clarke et al., 1970; Kepecs et al., 2005), whisking (Berg and Kleinfeld, 2003; Leiser and Moxon, 2007; Mitchinson et al., 2007) and locomotion (Parker and Clarke, 1990; Vásquez et al., 2002; Eilam et al., 2003), as well lacking control for technical issues, such as visual cues, forces, and even sounds produced by the electrical cable attached to the head implant and suspended over the animal. These issues could be addressed by adding appropriate controls. Thus, scent marks could be made visible in ultraviolet illumination (Desjardins et al., 1973). Additionally, traces of urinary proteins could be detected using a polyclonal antibody (Beynon and Hurst, 2004). The located scent marks could be then compared with the recordings of animal trajectories and behavioral data. Figure 1 illustrates a possible procedure that could clarify this issue.

A point of view should be acknowledged, stating that the contribution of olfaction is no longer a concern for the studies of rodent navigation in virtual environments, where odors left on the physical treadmill do not match virtual visual stimuli (Harvey et al., 2009; Dombeck et al., 2010; Chen et al., 2013; Domnisoru et al., 2013; Ravassard et al., 2013; Aronov and Tank, 2014; Aghajan et al., 2015). Yet, a closer look at these studies reveals several issues. For example, Figure $4 \mathrm{~A}$ in the study of Aronov and Tank (2014) shows a clearly non-uniform occupancy map for the virtual arena (e.g., zoom in their panel marked "Cell 2"). The map indicates that the rats visited different places with different probability and possibly behaved (whisked, sniffed, walked) differently depending on their location in the virtual environment. Similar non-uniform occupancy maps can be found in Figures 2A-C of Domnisoru et al. (2013). Furthermore, Movie S1 of Aronov and Tank shows that their rat sniffed the physical treadmill from time to time, i.e., exhibited an olfactory-related behavior. It seems reasonable to assume that the visual virtual stimuli may have triggered sniffing, which in turn may have modulated the activity of hippocampal neurons. The absence of any consistent smell in the virtual places may have facilitated the sniffing-induced neural responses rather than attenuating them. The modulation of hippocampal activity by sniffing has been known since O'Keefe's study of "misplace units" that responded to exploratory sniffing of places where a familiar object was missing, or a new object was found (O'Keefe, 1976). Additionally, sniffing activates the olfactory system even when no odors are present (Adrian, 1942; MacRides and Chorover, 1972). After all, rodent olfactory-related behaviors may not be easy to rule out, even in the virtual environments that uncouple visuallydefined places from the odors present in the real environment.

In addition to visual virtual environments, tactile (Sofroniew et al., 2015; Thurley and Ayaz, 2017) and olfactory-based (Radvansky and Dombeck, 2018) environments have been developed. While these studies help to elucidate the specific

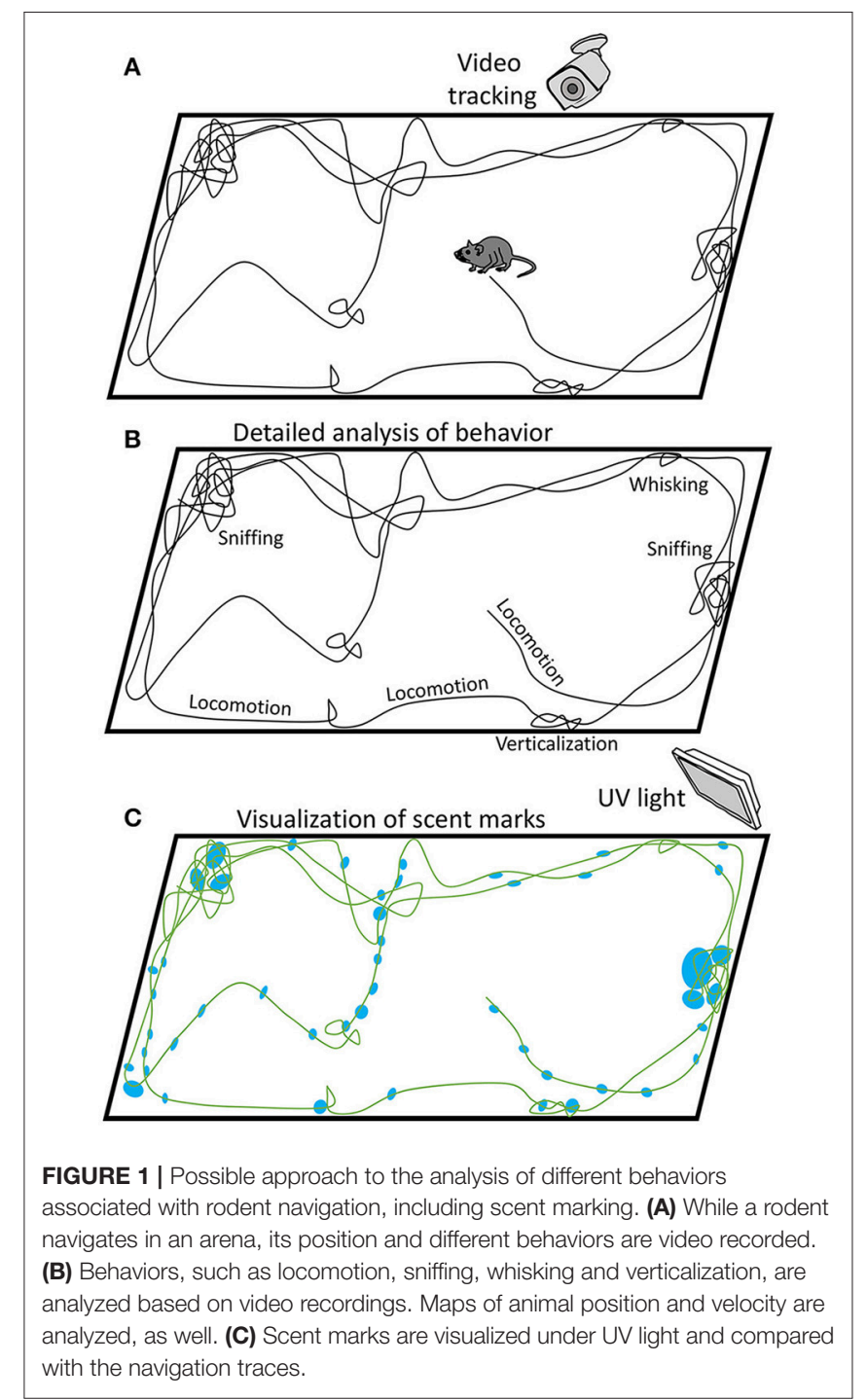

roles of different modalities in the formation of place fields, our comments still apply regarding the need for a more thorough analysis of different behaviors associated with rodent navigation.

In conclusion, the work of Zhang and Manahan-Vaughan not only contributes important findings on the formation of place fields based on olfactory inputs, but also instigates critical thinking regarding the methodological approaches in this field and the theories of hippocampal function.

\section{AUTHOR CONTRIBUTIONS}

All authors listed have made a substantial, direct and intellectual contribution to the work, and approved it for publication.

\section{FUNDING}

This work was supported by the Center for Bioelectric Interfaces of the Institute for Cognitive Neuroscience of the National Research University Higher School of Economics, RF Government grant, ag. No. 14.641.31.0003. 


\section{REFERENCES}

Adrian, E. (1942). Olfactory reactions in the brain of the hedgehog. J. Physiol. 100, 459-473. doi: 10.1113/jphysiol.1942.sp003955

Aghajan, Z. M., Acharya, L., Moore, J. J., Cushman, J. D., Vuong, C., and Mehta, M. R. (2015). Impaired spatial selectivity and intact phase precession in twodimensional virtual reality. Nat. Neurosci. 18:121. doi: 10.1038/nn.3884

Arleo, A., and Gerstner, W. (2000). Spatial cognition and neuro-mimetic navigation: a model of hippocampal place cell activity. Biol. Cybern. 83, 287-299. doi: 10.1007/s004220000171

Aronov, D., and Tank, D. W. (2014). Engagement of neural circuits underlying 2D spatial navigation in a rodent virtual reality system. Neuron $84,442-456$. doi: 10.1016/j.neuron.2014.08.042

Benjamini, Y., Lipkind, D., Horev, G., Fonio, E., Kafkafi, N., and Golani, I. (2010). Ten ways to improve the quality of descriptions of whole-animal movement. Neurosci. Biobehav. Rev. 34, 1351-1365. doi: 10.1016/j.neubiorev.2010.04.004

Berg, R. W., and Kleinfeld, D. (2003). Rhythmic whisking by rat: retraction as well as protraction of the vibrissae is under active muscular control. J. Neurophysiol. 89, 104-117. doi: 10.1152/jn.00600.2002

Beynon, R. J., and Hurst, J. L. (2004). Urinary proteins and the modulation of chemical scents in mice and rats. Peptides 25, 1553-1563. doi: $10.1016 /$ j.peptides.2003.12.025

Biella, G., and De Curtis, M. (2000). Olfactory inputs activate the medial entorhinal cortex via the hippocampus. J. Neurophysiol. 83, 1924-1931. doi: 10.1152/jn.2000.83.4.1924

Breathnach, A. (1960). The cetacean central nervous system. Biol. Rev. 35, 187-230. doi: 10.1111/j.1469-185X.1960.tb01414.x

Brodal, A. (1947). The hippocampus and the sense of smell. Brain 70, 179-222.

Burgess, N. (2014). The 2014 nobel prize in physiology or medicine: a spatial model for cognitive neuroscience. Neuron 84, 1120-1125. doi: 10.1016/j.neuron.2014.12.009

Chen, G., King, J. A., Burgess, N., and O'Keefe, J. (2013). How vision and movement combine in the hippocampal place code. Proc. Nat. Acad. Sci. U.S.A. 110, 378-383. doi: 10.1073/pnas.1215834110

Clarke, S., Panksepp, J., and Trowill, J. (1970). A method of recording sniffing in the free-moving rat. Physiol. Behav. 5, 125-126. doi: 10.1016/0031-9384(70)90024-7

DeFelipe, J., and Jones, E. G. (1988). Cajal on the Cerebral Cortex. An Annotated Translation of the Complete Writings. New York, NY: Oxford University Press.

Deshmukh, S. S., and Bhalla, U. S. (2003). Representation of odor habituation and timing in the hippocampus. J. Neurosci. 23, 1903-1915.

Desjardins, C., Maruniak, J., and Bronson, F. (1973). Social rank in house mice: differentiation revealed by ultraviolet visualization of urinary marking patterns. Science 182, 939-941. doi: 10.1126/science.182.4115.939

Dombeck, D. A., Harvey, C. D., Tian, L., Looger, L. L., and Tank, D. W. (2010). Functional imaging of hippocampal place cells at cellular resolution during virtual navigation. Nat. Neurosci. 13:1433. doi: 10.1038/nn.2648

Domnisoru, C., Kinkhabwala, A. A., and Tank, D. W. (2013). Membrane potential dynamics of grid cells. Nature 495:199. doi: 10.1038/nature11973

Drai, D., and Golani, I. (2001). SEE: a tool for the visualization and analysis of rodent exploratory behavior. Neurosci. Biobehav. Rev. 25, 409-426. doi: 10.1016/S0149-7634(01)00022-7

Eilam, D., Dank, M., and Maurer, R. (2003). Voles scale locomotion to the size of the open-field by adjusting the distance between stops: a possible link to path integration. Behav. Brain Res. 141, 73-81. doi: 10.1016/S0166-4328(02)00322-4

Fonio, E., Gordon, G., Barak, N., Winetraub, Y., Oram, T. B., and Ahissar, E. (2015). Coordination of sniffing and whisking depends on the mode of interaction with the environment. Isr. J. Ecol. Evol. 61, 95-105. doi: 10.1080/15659801.2015.1124656

Fyhn, M., Molden, S., Witter, M. P., Moser, E. I., and Moser, M.-B. (2004). Spatial representation in the entorhinal cortex. Science 305, 1258-1264. doi: 10.1126/science.1099901

Golani, I., Benjamini, Y., and Eilam, D. (1993). Stopping behavior: constraints on exploration in rats (Rattus norvegicus). Behav. Brain Res. 53, 21-33. doi: 10.1016/S0166-4328(05)80263-3

Gray, S., and Hurst, J. L. (1995). The effects of cage cleaning on aggression within groups of male laboratory mice. Anim. Behav. 49, 821-826. doi: 10.1016/0003-3472(95)80213-4
Harvey, C. D., Collman, F., Dombeck, D. A., and Tank, D. W. (2009). Intracellular dynamics of hippocampal place cells during virtual navigation. Nature 461, 941-946. doi: 10.1038/nature08499

Hurst, J. L., and Beynon, R. J. (2004). Scent wars: the chemobiology of competitive signalling in mice. Bioessays 26, 1288-1298. doi: 10.1002/bies.20147

Insausti, R., Marcos, P., Arroyo-Jimenez, M., Blaizot, X., and MartinezMarcos, A. (2002). Comparative aspects of the olfactory portion of the entorhinal cortex and its projection to the hippocampus in rodents, nonhuman primates, and the human brain. Brain Res. Bull. 57, 557-560. doi: 10.1016/S0361-9230(01)00684-0

Jacobs, L. F. (2012). From chemotaxis to the cognitive map: the function of olfaction. Proc. Nat. Acad. Sci. U.S.A. 109(Suppl. 1), 10693-10700. doi: 10.1073/pnas.1201880109

Johnson, R. P. (1973). Scent marking in mammals. Anim. Behav. 21, 521-535. doi: 10.1016/S0003-3472(73)80012-0

Kepecs, A., Uchida, N., and Mainen, Z. F. (2005). The sniff as a unit of olfactory processing. Chem. Senses 31, 167-179. doi: 10.1093/chemse/bjj016

Khan, A. G., Sarangi, M., and Bhalla, U. S. (2012). Rats track odour trails accurately using a multi-layered strategy with near-optimal sampling. Nat. Commun. 3:703. doi: $10.1038 /$ ncomms 1712

Krettek, J., and Price, J. (1977). Projections from the amygdaloid complex and adjacent olfactory structures to the entorhinal cortex and to the subiculum in the rat and cat. J. Comp. Neurol. 172, 723-752. doi: 10.1002/cne.901720409

Kulvicius, T., Tamosiunaite, M., Ainge, J., Dudchenko, P., and Wörgötter, F. (2008). Odor supported place cell model and goal navigation in rodents. $J$. Comput. Neurosci. 25, 481-500. doi: 10.1007/s10827-008-0090-x

Lavenex, P., and Schenk, F. (1996). Integration of olfactory information in a spatial representation enabling accurate arm choice in the radial arm maze. Learn. Mem. 2, 299-319. doi: 10.1101/lm.2.6.299

Lavenex, P., and Schenk, F. (1998). Olfactory traces and spatial learning in rats. Anim. Behav. 56, 1129-1136. doi: 10.1006/anbe.1998.0873

Leiser, S. C., and Moxon, K. A. (2007). Responses of trigeminal ganglion neurons during natural whisking behaviors in the awake rat. Neuron 53, 117-133. doi: 10.1016/j.neuron.2006.10.036

Luskin, M. B., and Price, J. (1983). The laminar distribution of intracortical fibers originating in the olfactory cortex of the rat. J. Comp. Neurol. 216, 292-302. doi: $10.1002 / \mathrm{cne} .902160306$

Maaswinkel, H., and Whishaw, I. Q. (1999). Homing with locale, taxon, and dead reckoning strategies by foraging rats: sensory hierarchy in spatial navigation. Behav. Brain Res. 99, 143-152. doi: 10.1016/S0166-4328(98)00100-4

MacDonald, C. J., Carrow, S., Place, R., and Eichenbaum, H. (2013). Distinct hippocampal time cell sequences represent odor memories in immobilized rats. J. Neurosci. 33, 14607-14616. doi: 10.1523/JNEUROSCI.1537-13.2013

MacRides, F., and Chorover, S. L. (1972). Olfactory bulb units: activity correlated with inhalation cycles and odor quality. Science 175, 84-87. doi: 10.1126/science.175.4017.84

Markus, E. J., Barnes, C. A., McNaughton, B. L., Gladden, V. L., and Skaggs, W. E. (1994). Spatial information content and reliability of hippocampal CA1 neurons: effects of visual input. Hippocampus 4, 410-421. doi: 10.1002/hipo.450040404

Mitchinson, B., Martin, C. J., Grant, R. A., and Prescott, T. J. (2007). Feedback control in active sensing: rat exploratory whisking is modulated by environmental contact. Proc. R. Soc. Lond. B Biol. Sci. 274, 1035-1041. doi: $10.1098 / \mathrm{rspb} .2006 .0347$

Moser, E. I., Kropff, E., and Moser, M.-B. (2008). Place cells, grid cells, and the brain's spatial representation system. Annu. Rev. Neurosci. 31, 69-89. doi: 10.1146/annurev.neuro.31.061307.090723

Moser, E. I., and Moser, M.-B. (2013). Grid cells and neural coding in high-end cortices. Neuron 80, 765-774. doi: 10.1016/j.neuron.2013. 09.043

O'Keefe, J. (1976). Place units in the hippocampus of the freely moving rat. Exp. Neurol. 51, 78-109. doi: 10.1016/0014-4886(76)90055-8

O'keefe, J., and Conway, D. (1978). Hippocampal place units in the freely moving rat: why they fire where they fire. Exp. Brain Res. 31, 573-590. doi: 10.1007/BF00239813

O'Keefe, J., and Dostrovsky, J. (1971). The hippocampus as a spatial map. Preliminary evidence from unit activity in the freely-moving rat. Brain Res. 34, 171-175. doi: 10.1016/0006-8993(71)90358-1 
O'Keefe, J., and Nadel, L. (1978). The Hippocampus as a Cognitive Map. Oxford: Clarendon Press.

Olton, D. S., and Collison, C. (1979). Intramaze cues and "odor trails" fail to direct choice behavior on an elevated maze. Anim. Learn. Behav. 7, 221-223.

Parker, A. J., and Clarke, K. A. (1990). Gait topography in rat locomotion. Physiol. Behav. 48, 41-47. doi: 10.1016/0031-9384(90)90258-6

Patzke, N., Spocter, M. A., Bertelsen, M. F., Haagensen, M., Chawana, R., Mohammed, O. B., et al. (2015). In contrast to many other mammals, cetaceans have relatively small hippocampi that appear to lack adult neurogenesis. Brain Struct. Funct. 220, 361-383. doi: 10.1007/s00429-013-0660-1

Porter, J., Anand, T., Johnson, B., Khan, R. M., and Sobel, N. (2005). Brain mechanisms for extracting spatial information from smell. Neuron 47, 581-592. doi: 10.1016/j.neuron.2005.06.028

Radvansky, B. A., and Dombeck, D. A. (2018). An olfactory virtual reality system for mice. Nat. Commun. 9:839. doi: 10.1038/s41467-018-03262-4

Ravassard, P., Kees, A., Willers, B., Ho, D., Aharoni, D., Cushman, J., et al. (2013). Multisensory control of hippocampal spatiotemporal selectivity. Science 340, 1342-1346. doi: 10.1126/science.1232655

Roberts, S. A., Davidson, A. J., McLean, L., Beynon, R. J., and Hurst, J. L. (2012). Pheromonal induction of spatial learning in mice. Science 338, 1462-1465. doi: $10.1126 /$ science. 1225638

Roberts, S. A., Simpson, D. M., Armstrong, S. D., Davidson, A. J., Robertson, D. H., Hurst, J. L., et al. (2010). Darcin: a male pheromone that stimulates female memory and sexual attraction to an individual male's odour. BMC Biol. 8:75. doi: $10.1186 / 1741-7007-8-75$

Room, P., Groenewegen, H., and Lohman, A. (1984). Inputs from the olfactory bulb and olfactory cortex to the entorhinal cortex in the cat. Exp. Brain Res. 56, 488-496. doi: 10.1007/BF00237989

Save, E., Cressant, A., Thinus-Blanc, C., and Poucet, B. (1998). Spatial firing of hippocampal place cells in blind rats. J. Neurosci. 18, 1818-1826.

Save, E., Nerad, L., and Poucet, B. (2000). Contribution of multiple sensory information to place field stability in hippocampal place cells. Hippocampus 10, 64-76. doi: 10.1002/(SICI) 1098-1063(2000)10:1 <64::AID-HIPO7>3.0.CO;2-Y

Schwerdtfeger, W. K., Buhl, E. H., and Germroth, P. (1990). Disynaptic olfactory input to the hippocampus mediated by stellate cells in the entorhinal cortex. J. Comp. Neurol. 292, 163-177. doi: 10.1002/cne.902920202

Shapiro, M. L., Tanila, H., and Eichenbaum, H. (1997). Cues that hippocampal place cells encode: dynamic and hierarchical representation of local and distal stimuli. Hippocampus 7, 624-642. doi: 10.1002/(SICI)10981063(1997)7:6\&lt;624::AID-HIPO5\&gt;3.0.CO;2-E

Small, W. S. (1901). Experimental study of the mental processes of the rat. II. Am. J. Psychol.12, 206-239. doi: 10.2307/1412534

Sofroniew, N. J., Vlasov, Y. A., Hires, S. A., Freeman, J., and Svoboda, K. (2015). Neural coding in barrel cortex during whisker-guided locomotion. Elife 4:e12559. doi: 10.7554/eLife.12559

Stopka, P., and MacDonald, D. W. (2003). Way-marking behaviour: an aid to spatial navigation in the wood mouse (Apodemus sylvaticus). BMC Ecol. 3:3. doi: 10.1186/1472-6785-3-3

Thomas, J. A., and Kastelein, R., A. (2013). Sensory Abilities of Cetaceans: Laboratory and Field Evidence. Springer Science \& Business Media.

Thonhauser, K. E., Raveh, S., Hettyey, A., Beissmann, H., and Penn, D. J. (2013). Scent marking increases male reproductive success in wild house mice. Anim. Behav. 86, 1013-1021. doi: 10.1016/j.anbehav.2013. 09.004

Thurley, K., and Ayaz, A. (2017). Virtual reality systems for rodents. Curr. Zool. 63, 109-119. doi: $10.1093 /$ cz/zow070

Tomlinson, W. T., and Johnston, T. D. (1991). Hamsters remember spatial information derived from olfactory cues. Learn. Behav. 19, 185-190. doi: $10.3758 / \mathrm{BF} 03197875$

Vanderwolf, C. (1992). Hippocampal activity, olfaction, and sniffing: an olfactory input to the dentate gyrus. Brain Res. 593, 197-208. doi: 10.1016/0006-8993(92)91308-2

Vanderwolf, C. (2001). The hippocampus as an olfacto-motor mechanism: were the classical anatomists right after all? Behav. Brain Res. 127, 25-47. doi: 10.1016/S0166-4328(01)00354-0

van Rijzingen, I. M., Gispen, W. H., and Spruijt, B. M. (1995). Olfactory bulbectomy temporarily impairs Morris maze performance: an ACTH (4-9) analog accellerates return of function. Physiol. Behav. 58, 147-152. doi: 10.1016/0031-9384(95)00032-E

Vásquez, R. A., Ebensperger, L. A., and Bozinovic, F. (2002). The influence of habitat on travel speed, intermittent locomotion, and vigilance in a diurnal rodent. Behav. Ecol. 13, 182-187. doi: 10.1093/beheco/13.2.182

Wallace, D. G., Gorny, B., and Whishaw, I. Q. (2002). Rats can track odors, other rats, and themselves: implications for the study of spatial behavior. Behav. Brain Res. 131, 185-192. doi: 10.1016/S0166-4328(01)00384-9

Welker, W. (1964). Analysis of sniffing of the Albino rat 1. Behaviour 22, 223-244. doi: 10.1163/156853964X00030

Wiener, S. I., Korshunov, V. A., Garcia, R., and Berthoz, A. (1995). Inertial, substratal and landmark cue control of hippocampal CA1 place cell activity. Eur. J. Neurosci. 7, 2206-2219. doi: 10.1111/j.1460-9568.1995.tb 00642.x

Wilson, R., and Steward, O. (1978). Polysynaptic activation of the dentate gyrus of the hippocampal formation: an olfactory input via the lateral entorhinal cortex. Exp. Brain Res. 33, 523-534. doi: 10.1007/BF00235572

Yaski, O., Portugali, J., and Eilam, D. (2011). Arena geometry and path shape: when rats travel in straight or in circuitous paths? Behav. Brain Res. 225, 449-454. doi: 10.1016/j.bbr.2011.07.055

Youngentob, S. L., Mozell, M. M., Sheehe, P. R., and Hornung, D. E. (1987). A quantitative analysis of sniffing strategies in rats performing odor detection tasks. Physiol. Behav. 41, 59-69. doi: 10.1016/0031-9384(87)90131-4

Zhang, S., and Manahan-Vaughan, D. (2015). Spatial olfactory learning contributes to place field formation in the hippocampus. Cereb. Cortex 25, 423-432. doi: $10.1093 /$ cercor/bht239

Conflict of Interest Statement: The authors declare that the research was conducted in the absence of any commercial or financial relationships that could be construed as a potential conflict of interest.

Copyright $\odot 2018$ Lebedev and Ossadtchi. This is an open-access article distributed under the terms of the Creative Commons Attribution License (CC BY). The use, distribution or reproduction in other forums is permitted, provided the original author(s) and the copyright owner are credited and that the original publication in this journal is cited, in accordance with accepted academic practice. No use, distribution or reproduction is permitted which does not comply with these terms. 